\title{
PANORAMA HISTÓRICO Y PROFUNDIDAD \\ DE LA LITERATURA INFANTIL Y JUVENIL
}

\section{Ángel Pérez Martínez* \\ Universidad del Pacifico}

Resumen: La literatura infantil y juvenil es un campo de estudio que todavía no se ha explorado adecuadamente. Suele presentarse desde el mero presente sin recurrir a su compleja historia y orígenes. Es importante recordar el valor de los clásicos, los cuales a la larga desarrollan ciertas capacidades interiores en las personas y experiencias paralelas como la lectura compartida con los adultos.

Si bien se presentan tantas listas de libros, estos pueden carecer de calidad y ser usados como una fachada educativa cuando realmente no lo son. El mundo de la LIJ no es simple y presenta grandes desafíos. En este artículo se intenta dar una rápida mirada a la historia y a las posibilidades temáticas de la LIJ.

Palabras clave: literatura infantil, literatura juvenil, Historia literaria, literatura.

Aвstract: The children and youth's literature is a field of study that has not yet been adequately explored. Usually come along from the very present

* Ángel Pérez Martínez es escritor de literatura infantil. Ganador del Premio de Literatura Infantil «El Barco de Vapor» (2009) y del Premio Internacional Amado Alonso (2004). Es doctor en Literatura Española y especialista en Filología Hispánica. Ejerce la docencia universitaria en el Departamento de Humanidades de la Universidad del Pacífico y es miembro del Centro de Investigación de esta casa de estudios. Es autor de Memorias secretas de un librero (Madrid, 2003), Perengrín XXVI (Lima, 2007) y El ladrón de monosílabos (Lima, 2009). 
without fall back to its complex history and origins. It's important to remember the value of the classics, which eventually develop certain inner capacities in people and parallel experiences as shared reading with adults

While presenting many list of books, they may lack quality and be used as an educational cover when they are not. The world of the children and youth's literature is not simple and it present big challenges. This article attempts to give a quick look at the history and thematic possibilities of the children's literature

KeY words: Children's Literature, Youth Literature, Literary History, Literature

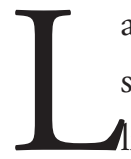

a aproximación a la LIJ que nos ofrece la crítica en nuestro medio suele tener una serie de aproximaciones algo precarias. Listas de libros realizadas por críticos con horizontes limitados a un tiempo y espacio específico. Listas de los libros más vendidos que no necesariamente son los mejores. Listas de libros promovidas por las editoriales y definidas por el impacto comercial y publicitario. Y a esto se le suma los programas llamados planes lectores, que en muchos casos y lamentablemente, ahondan en la falta de calidad de las lecturas escogidas y que son aprovechados por las editoriales, los colegios y los políticos como una fachada educativa que no lo es tanto. A mi parecer este es uno de los problemas del panorama literario infantil y juvenil en nuestro país. Quiero mencionar, para ser justos, que no todo es negativo, y de ello son prueba las diversas iniciativas que se llevan a cabo en el Perú sobre LIJ. Uno de los países de la región donde más se ha hecho en los últimos años en esta línea es el Perú. Pero quizás el principal problema sea la ignorancia acerca de sus orígenes, su tradición y sobre todo los clásicos que surgen desde esa historia.

Aunque la tradición no defina la nobleza de un arte, en cierto sentido nos permite comprender su genealogía. La LIJ, que ha tenido un despliegue considerable en estas últimas décadas, para muchos no pasa 
de ser un asunto de niños. Una pregunta previa habría de ser, primero, quiénes son los niños. Hay una especie de contradicción entre los grandes desarrollos de la pedagogía actual y la simplificación y tensiones a la que han sido sometidos los niños en nuestros días. Sin embargo, y siempre lo he defendido, la LIJ presenta una compleja historia, una compleja teoría y una compleja actualidad en donde se encuentran tesoros valiosísimos y donde existe un campo de estudio que todavía no se ha explorado adecuadamente.

Mi intención es dar una rápida mirada a la historia y las posibilidades temáticas de la LIJ. He querido, de alguna manera seguir una recomendación que Ortega y Gasset hacía en 1928 a los niños españoles presentando un texto escolar:

Mi oposición a la escolaridad del Quijote no se funda en un practicismo miope. No me estorba el Quijote en la escuela porque sea un libro añejo, inadaptado a la realidad contemporánea; al contrario, me parece un libro de espíritu demasiado moderno para el ambiente de las aulas infantiles, que debe mantenerse perennemente antiguo, primitivo, siempre entre luces y rumores de aurora. La discriminación entre lo que han de leer y lo que no han de leer los niños debiera ser, por lo menos en principio, bastante clara, y derivarse como un corolalio de la noción de vida infantil. (Ortega y Gasset 2006 [1920]: 421)

Al principio los niños escuchaban las historias narradas por boca de los adultos, ayudados por pinturas, actuaciones, música y otras expresiones artísticas. 
La historia de la LIJ y la historia de la literatura universal beben de la misma fuente. Los niños son lectores y oyentes de las narraciones adultas a veces adaptadas y a veces no. Este era el material narrativo y natural para todos. Quizás un punto de quiebre sea el mundo griego. Pues los mitos griegos y las narraciones homéricas han sido luego las grandes anclas de los desarrollos de la LIJ. Las formas de adaptación oral son las más naturales y surgen desde un tipo de pedagogía natural que hoy todavía utilizamos. En el mundo clásico tanto los mitos, como las narraciones epopéyicas tienen un material enorme para ser asumidos por la mente infantil. De alguna manera la estructura de las narraciones y su contenido son asunciones adaptadas, acción que se dificulta enormemente en el caso de muchas obras de la modernidad. Por ello podríamos decir que los canales de comunicación entre la LIJ y la literatura adulta en la época clásica son mayores y tienen menores dificultades que en la actualidad. Hay una hipótesis que sería interesante trabajar: la de que la LIJ no es un invento exclusivo de la modernidad, y que no responde a los desarrollos de ciencias como la Psicología y la Pedagogía. Un cuestionamiento de estas ideas quizás pudiera solventarse desde una literatura comparada entre el mundo infantil y el mundo adulto.

En la Edad Media la cultura pedagógica estaba bien desarrollada en el nivel oral y es cierto que tanto menores como mayores estaban familiarizados con las mismas narraciones. Mediante su labor catequética los eclesiásticos enseñaban mediante las historias bíblicas, donde los relatos adaptados a cada caso presentaban un enorme abasto de hechos sobre los cuales hablar, profundizar o simplemente contar. Y muchos de ellos eran iluminados por estatuas, pinturas y bellos vitrales cómo los de las catedrales góticas. Habían pocos libros dirigidos exclusivamente para el público infantil: silabarios, abecedarios o bestiarios, a lo que se sumaba que el uso del libro era muy difícil. Sin embargo, había una gran cantidad de 
leyendas, cuentos e historias que los niños escuchaban y aprendían. Parte de la tradición oral en cada país contaba con un buen grupo de cuentos que enseñaban lecciones o simplemente entretenían. Un elemento beneficioso de esta primera etapa es que las narraciones eran explicadas, ya sea por los catequistas o aquellos mayores que las contaban de tal manera que la lectura o transmisión era comunitaria. En muchos casos habría una interpretación que ayudaba a objetivar e internalizar lo escuchado.

Hasta aquí el mundo de la LIJ no es nada simple y nada reducido. Se necesita investigar mucho más acerca de estos asuntos para comprender como esa conexión entre la estética adulta y la estética infantil era bastante sugerente y poderosa en la antiguedad.

Luego de que Gütemberg en 1450 inventara la imprenta, los libros empiezan a difundirse con cada vez mayor profusión. Entre las primeras lecturas publicadas para el público infantil habían clásicos griegos: la Fábulas de Esopo (620-560 a. C.), y adaptaciones de la Sagrada Escritura tales como el Antiguo Testamento para los niños de Hans Holbein (¿1497?1543), publicado póstumamente en 1549. El francés François Fenelón (1651-1715) escribió en 1699 Las aventuras de Telémaco, que fue la primera novela escrita expresamente para un niño, en este caso el futuro rey de Francia, y tenía una aproximación formativa. Los descubrimientos marinos del los siglos XVI y XVII impulsan una nueva narrativa de aventuras que desarrollarán obras con trasfondos roussonianos como Robinson Crusoe de Daniel Defoe (1660-1731) o algunas con visos críticos tales como Los viajes de Gulliver de Swift (1667-1735) en 1726.

Muchas de estas obras tenían un alto nivel narrativo o descriptivo que luego se ha perdido por diversas razones. Estaban dirigidas, salvo algunas excepciones, a cualquiera que deseara leerlas, lo cual nos debería hacer pensar en que la moderna distinción «novela de adultos», o «novela infantil» 
pudiera, en ciertas ocasiones, ser arbitraria. Habría que detenerse a ver si las razones de esa división son consistentes o no. Los temas de aventuras y viajes apelaban especialmente la sensibilidad del niño o del joven y se convertían en vehículos para su despliegue y ansia de conocer, pero también la gente mayor leía dichas historias con gran gusto; por ello alentaban a los menores en su lectura.

Ya entrado el siglo XVII y durante los dos siguientes habrá un acento en la recuperación de las antiguas leyendas o cuentos tradicionales. Recuperación reclamada por los ilustrados pero que se encontraba ya en el acervo cultural de universidades, monasterios y tradiciones nacionales. Vienen las colecciones del galo Perrault (1628-1703) o el napolitano Basile (1575-1632). Otras recopilaciones que marcan la historia de este tipo de literatura es la de los hermanos Grimm —Jacob Ludwig Karl (1785-1863) y Wilhelm Karl (1786-1859)—, que recogen la tradición germana; o las de Afanásiev (1826-1871) que hace lo mismo en Rusia. Una de los compendios que mayor éxito tuvieron fue la de cuentos orientales de Las mily una noches, narrando historias de la tradición persa, hindú, egipcia y árabe. En España encontramos a dos fabulistas tradicionales: Tomás de Iriarte (1750-1791) y el ilustrado Félix María Samaniego (1745-1801). Como creador de nuevas historias infantiles no podemos dejar de mencionar al danés Hans Christian Andersen (1805-1875) que se convertirá en uno de los autores de cuentos de hadas más conocidos.

A partir del siglo XIX, los desarrollos de la LIJ son cada vez mayores y empieza esta capacidad de atender a gustos y preferencias entre un público cada vez más sofisticado.

Conviene ahora hacer algunas distinciones en cuanto a los tipos de literatura infantil y juvenil que se diversifica en esta parte de la historia en la que los especialistas consideran algunas líneas fundamentales. Dichas son la 
PANORAMA HISTÓRICO Y PROFUNDIDAD DE LA LITERATURA INFANTIL Y JUVENIL

llamada literatura de aventuras, de fantasía o de iniciación. Si bien en una misma obra las líneas se pueden mezclar, hay alguna que permanece más notoria que las otras. ${ }^{1}$

En cuanto a las de aventuras podemos mencionar, además de las ya señaladas, La isla misteriosa del prolífico Julio Verne (1828-1905), quien también escribirá Los hijos del Capitán Grant, La vuelta al mundo en ochenta días y otras más. Un éxito inmediato tendría Las minas del Rey Salomón de Rider Haggard (1856-1925) que narra las peripecias de Allan Quatermain, La llamada de lo salvaje de Jack London (1876-1916), con visos heroicos dentro de un realismo dramático. Siempre conscientes de los vacíos de una lista tan resumida recordaremos las novelas épicas de autores como Walter Scott (1771-1832), quien trajo narraciones como Ivanhoe, El talismán; o Lewis Wallace (1827-1905), quien escribió Ben-Hur.

Entre la literatura de fantasía señalaremos una obra que resulta emblemática del llamado nonsense, o corriente de la falta de sentido. Se trata de Alicia en el Pais de las Maravillas de Lewis Carroll (1832-1898) donde el autor hace un uso constante de la lógica y la sicología. Luego vendrían libros como El mago de Oz del norteamericano Baum (1856-1919), Peter Pan de James Barrie (1860-1937), El viento en los sauces de Grahame (1859-1932), o El mundo de Pooh de Milne (1882-1956). En todas las obras nombradas encontraremos algún mensaje, idea o marco filosófico soterrado. Ya sea en forma de crítica hacia la realidad, desencanto nihilista, o de utopía en un mundo imaginario, los autores no son solo literatos dedicados a divertir al público infantil; hay visiones sobre la vida que conviene tener en cuenta.

1 He seguido algunas de las intuiciones de González 2006, Garralón 2002, Ortega y Gasset 2006, y Ortega y Gasset 2006 [1920]. 
El Principito de Antoine de Saint-Exupéry (1900-1944) nos demuestra que un pequeño libro puede traer un torrente de simbología y mensajes, Las Crónicas de Narnia del británico C.S. Lewis (1898-1963) descubren mundos paralelos con realidades teológicas, o la trilogía de Tolkien (1892-1973), El Señor de los Anillos, cuya profusión filológica a veces niebla su ejemplar sentido épico.

La literatura de iniciación es aquella que versa sobre el crecimiento y despliegue del protagonista que muchas veces es un niño o un joven. El enfrentamiento a los retos y dificultades, la búsqueda de un tesoro, o la superación personal son elementos presentes en donde el protagonista crecerá a la altura de las circunstancias. Las historias donde el personaje principal es un niño llegaran de la mano de dos grandes maestros: el inglés Charles Dickens (1812-1870) con sus inolvidables Oliver Twist, y David Copperfield, y el norteamericano Mark Twain (1835-1910), creador de las historias de Tom Sawyer donde hay una crítica a la pedagogía tradicional. Ruyard Kipling (18651936) tiene en su haber varios clásicos de este género. Tales son su Libro de la selva, donde la vida de Mowgli vuelve a plantear la cuestión sobre la bondad natural del ser humano. En Kim —en la misma tendencia ideológica-, los conflictos sociales se describen con crudeza. Son de iniciación también novelas más intimistas como Corazón de Edmundo de Amicis (1846-1908) o Mujercitas de Louise May Alcott (1832-1888). Un clásico iniciático que se cruza con el rubro de fantasía ha sido La historia interminable del alemán Michael Ende (1924-1995).

Hoy por hoy no solo son cercanas sino que las novelas de iniciación han causado una gran impresión en los públicos de todas las edades con la saga de la irlandesa J. K. Rowling.

Hay muchos autores más en los rubros mencionados. La segunda mitad del siglo XX vio nacer una enorme cantidad de ellos. Elaborar una 
lista excedería las dimensiones de este artículo. Quizás conozcamos algunos de oídas o hayamos visto alguna película basada en sus novelas: Gripe, Dahl, Nöstlinger, Preussler, Muñoz Martín, del Amo, Gisbert, Sierra i Fabra, Olaizola, Mateos, Fine, Nilsson, Brezan, Goscinny, Ross, Travers, Lindo, Matute, Gaite, Auster, Rodari, Lindgren, Ionescu son algunos de los apellidos de estos creadores de aventuras para niños y jóvenes. ${ }^{2}$

Estos son algunos hitos que merecen una mayor exploración por parte de la teoría de la literatura. En mi opinión, la LIJ tiene o debería tener un lugar en el mundo académico, específicamente en las facultades de filología. Uno de los grandes peligros es dejar al azar comercial o político las listas de libros sugeridos para nuestro público. No se trata de etiquetar las obras, pero sí de hacer una distinción básica entre las que traen aportes valiosos, las que no y las que contienen un mero afán propagandístico. También es conveniente saber quién es el autor, o por qué escribió su obra. Incluso en algunas adaptaciones conviene ser perspicaces y no tener una actitud ingenua. A veces pensamos que porque la historia viene con el sello de una editorial importante el asunto está resuelto. Las listas de libros más vendidos no bastan para realizar elecciones adecuadas.

Uno de los problemas actuales es que los adultos no leen lo mismo que los pequeños. Tal vez era un óbice menor hace algunos siglos, cuando el padre y el hijo leían la misma historia, por eso es bueno acompañar a los niños en la lectura. Es provechosa la costumbre de contar los cuentos a los niños y con los más mayores comentar las lecturas realizadas. El compartir lo leído es una valiosa experiencia familiar. Alentar la lectura de los clásicos nunca está de más. Es una tarea difícil porque la televisión y el cine acostumbran a

2 Una excelente y rápida guía histórica es la Historia portátil de la literatura infantil y juvenil (Garralón 2002). 
las inteligencias a otro tipo de lecturas más dinámicas y explosivas, pero a la larga los clásicos desarrollan ciertas capacidades interiores en las personas que de otra manera quedarían agarrotadas. La prosa precisa y trabajada de siglos pasados acostumbra a la mente a la asimilación de conceptos, el ejercicio de la memoria y a la reproducción objetiva mediante la imaginación. En ellos se leen descripciones tan delimitadas que reclama comprensión, concentración y análisis. Hace algunos cientos de años los lectores menudos tenían un despliegue de facultades intelectuales, intuitivas y creativas que poco a poco ha ido disminuyendo. No quiere decir que los antiguos autores estuvieran exentos de errores, ni que las técnicas actuales no sirvan, pero en esta específica cualidad los antiguos tenían expresiones que hoy se desaprovechan porque a los jóvenes les resulta más difícil leerlas.

A pesar de todo ello la literatura infantil y juvenil mantiene en ciertos cauces salvaguardas contra los embates en contra de la estética. Son un buen grupo los autores que presentan narraciones con mucha calidad. Normalmente las narraciones de calidad suelen tener una gran conexión con los grandes temas de la literatura clásica.

Volvemos otra vez a una de las ideas de Ortega:

Por esto yo creo que imágenes como las de Hércules y Ulises serán eternamente escolares. Gozan de una irradiación inmarcesible, generatriz de inagotables entusiasmos. Un pedagogo practicista despreciará estos mitos y en lugar de tales imágenes fantásticas procurará desde el primer día implantar en el alma del niño ideas exactas de las cosas. «Hechos, nada más que hechos!», grita el personaje de los Tiempos difíciles, a quien luego hace coro monsuir Homaiss. Para mí, los hechos deben ser el final de la educación: primero mitos, sobre todo mitos. Los hechos no 
provocan sentimientos. ¿Qué sería, no ya de un niño, sino del hombre más sabio de la tierra, si súbitamente fueran aventados de su alma todos los mitos eficaces? El mito, la noble imagen fantástica, es una función interna sin la cual la vida psíquica se detendría paralítica. Ciertamente que nos proporciona una adaptación intelectual a la realidad. El mito no encuentra en el mundo externo su objeto adecuado. Pero en cambio suscita en nosotros las corrientes inducidas de los sentimientos que nutren el pulso vital, mantienen a flote nuestro afán de vivir y aumentan la tensión de nuestros más profundos resortes biológicos. El mito es la hormona psíquica. (Ortega y Gasset 2006 [1920]: 420)

Un mundo de mitos necesarios — más que de sueños - nos espera en los libros para niños. Quizás no sea tarde para empezar, y tal vez allí encontremos ciertos criterios que son difíciles descubrir en nuestra vida adulta. Por todo ello vale la pena adentrarse en él aunque ya seamos mayores para hacerlo. 


\section{BIBLIOGRAFÍA}

Garralón, Ana 2002

Historia portátil de la literatura infantil y juvenil. Madrid: Anaya.

GonzÁLEZ, Luis Daniel 2006 Bienvenidos a la Fiesta. Diccionario de autores de literatura infantily juvenil. Madrid: CIE Dossat.

Ortega y Gasset, José

2006

La deshumanización del arte e ideas sobre la novela. En Ortega y Gasset, J. Obras Completas. Vol. III. Madrid: Fundación Ortega y Gasset y Santillana Ediciones.

2006b [1920] Obras Completas. En Ortega y Gasset, J. Ensayos filosóficos

Vol. III. Madrid: Fundación Ortega y Gasset y Santillana Ediciones. 